\title{
Outcomes in GLP-1 RA-Experienced Patients Switching to Once-Weekly Semaglutide in a Real- World Setting: The Retrospective, Observational EXPERT Study
}

Ildiko Lingvay · Andreas R. Kirk · Søren Lophaven • Michael L. Wolden •

Jay H. Shubrook

Received: November 18, 2020 / Accepted: January 23, 2021 / Published online: February 17, 2021

(c) The Author(s) 2021

\section{ABSTRACT}

Introduction: Glucagon-like peptide-1 receptor agonists (GLP-1 RAs) are highly effective for glycaemic control and weight loss in patients with type 2 diabetes (T2D). In this retrospective, observational study, we analysed glycated haemoglobin (HbA1c) and weight following switching to semaglutide from any other GLP-1 RA, using US electronic health records and prescription data.

Methods: Adults ( $\geq 18$ years old) with T2D required at least one prescription for injectable semaglutide at index date (treatment switch), at least one prescription for any other GLP-1 RA in the previous 365 days, a baseline

Supplementary Information The online version contains supplementary material available at https:// doi.org/10.1007/s13300-021-01010-4.

I. Lingvay $(\bowtie)$

Department of Internal Medicine/Endocrinology and Department of Population and Data Sciences, University of Texas Southwestern Medical Center, Dallas, TX, USA

e-mail: Ildiko.Lingvay@UTSouthwestern.edu

A. R. Kirk · M. L. Wolden

Novo Nordisk A/S, Søborg, Denmark

S. Lophaven

Omicron ApS, Roskilde, Denmark

J. H. Shubrook

College of Osteopathic Medicine, Touro University

California, Vallejo, CA, USA
HbA1c and/or weight measurement in the 90 days pre-index and a follow-up measurement at 180 and 365 days post-index. HbA1c and weight cohorts were analysed separately using an ANCOVA model. Sensitivity analyses were conducted in patients with at least two prescriptions for pre-switch GLP-1 RA. A secondary analysis compared subgroups receiving different GLP-1 RAs pre-switch.

Results: Patients with HbA1c $(n=710)$ and weight $(n=921)$ data had similar baseline characteristics. Significant reductions in HbA1c at 6 months $(0.7 \% ; 95 \%$ confidence interval $[\mathrm{CI}]-0.8,-0.6)$ were sustained at 12 months. Weight reductions were significant at 6 months $(-2.1 \mathrm{~kg} ; 95 \% \mathrm{CI}-2.6,-1.6)$ and greater at 12 months $(-2.8 \mathrm{~kg} ; \quad 95 \% \quad \mathrm{CI}-3.9,-1.8)$. These patterns were consistent with the twoprescription sensitivity analysis and independent of the pre-switch GLP-1 RA.

Conclusion: Switching to injectable semaglutide from any other GLP-1 RA was associated with significant improvements in glycaemic control and weight. Our findings support decision-making in clinical practice in patients with an indication to switch between GLP-1 RAs.

Keywords: Database research; GLP-1 receptor agonists; Glycaemic control; Observational study; Type 2 diabetes; Weight loss 


\section{Key summary points}

\section{Why carry out this study?}

Although treatment switches between glucagon-like peptide-1 receptor agonists (GLP-1 RAs) occur frequently as part of treatment strategies for type 2 diabetes (T2D), relatively little is known about clinical outcomes following such a switch.

In this retrospective, observational study using US data, we examined glycated haemoglobin (HbA1c) and weight changes from baseline in patients with T2D who switched to injectable semaglutide from any other GLP-1 RA.

\section{What was learned from the study?}

Switching to semaglutide was associated with significant reductions in HbA1c after 6 months, which were sustained at 12 months. Weight reductions were significant at 6 months following treatment switch, and were greater at 12 months.

Our results provide confirmation that switching to semaglutide can be associated with significant improvements in glycaemic control and weight in patients with an indication to switch between GLP-1 RAs; these findings can be used to support decision-making in clinical practice.

\section{DIGITAL FEATURES}

This article is published with digital features, including a summary slide, to facilitate understanding of the article. To view digital features for this article go to https://doi.org/10.6084/ m9.figshare.13622807.

\section{INTRODUCTION}

Glucagon-like peptide-1 receptor agonists (GLP1 RAs), a class of incretin-based therapies for the treatment of type 2 diabetes (T2D), have been shown to be highly effective for both glycaemic control and weight loss, and are associated with a low risk of hypoglycaemia [1]. The American Diabetes Association recommends long-acting GLP-1 RAs as add-on to metformin in patients who have atherosclerotic cardiovascular disease (CVD), as well as in those who have not achieved glycaemic control. These agents may be used as first-line treatment in patients for whom metformin is not tolerated or is contraindicated, or in combination with other glucose-lowering agents, including insulin [2].

Multiple GLP-1 RA products have been approved for the treatment of T2D. The first GLP-RA, twice-daily exenatide, was approved in the USA in 2005 [3] and, most recently, semaglutide received approval for administration by injection in 2017 [4] and in an oral formulation in 2019 [5]. Consequently, clinicians are presented with a range of available GLP-1 RAs when making treatment decisions. A major consideration is the choice between a short-acting and a long-acting GLP-1 RA. The latter option is typically associated with fewer gastrointestinal side effects than manifest with short-acting GLP-1 RAs. In addition, the onceweekly administration schedules of long-acting GLP-1 RAs may be linked to improved adherence and persistence on medication [6]. Convenience, ease of administration, comorbidities and concomitant medications all need to be taken into account when selecting the most appropriate GLP-1 RA [6], as well as efficacy. In the Semaglutide Unabated Sustainability in Treatment of Type 2 Diabetes (SUSTAIN) clinical trial programme, semaglutide $1 \mathrm{mg}$ was associated with greater reductions in glycated haemoglobin (HbA1c) and weight than exenatide extended-release $2 \mathrm{mg}$ [7], dulaglutide $1.5 \mathrm{mg}$ [8] and liraglutide $1.2 \mathrm{mg}$ [9].

In a real-world study summarizing data collected from five European countries plus Canada in 2015-2016, between 4 and 24\% of patients had switched treatments at 1 year after 
their first GLP-1 RA prescription [10]. Furthermore, switching between different GLP-1 RA products is not uncommon. A recent review explored potential triggers for such treatment decisions and identified many factors, ranging from treatment effectiveness and side effects to changes in pharmacy benefit coverage and patient preference [11]. The cardiovascular benefits associated with certain GLP-1 RAs may also prompt treatment switching within the class [12].

Information regarding clinical outcomes after a switch within the GLP-1 RA class is limited. There are no randomized controlled trials (RCTs) exploring this question, and only a small number of observational studies have assessed outcomes after treatment switch [13, 14]; therefore, the use of real-world data can help to quantify the clinical effects of such a treatment change. We addressed this evidence gap by designing a real-world study that used data from a large US electronic health records (EHR) database to assess the changes in HbA1c and body weight in patients who switched to onceweekly injectable semaglutide from any other GLP-1 RA.

\section{METHODS}

\section{Data Source}

EHR and prescription data were extracted from the IBM Explorys EHR database (IBM Watson Health, Armonk, NY, USA), allowing clinical outcomes to be linked to treatment use. The database contains de-identified inpatient and outpatient information, provided with informed consent [15], on more than 63 million patients from multiple healthcare systems [16]. Approval by an ethics committee was not required for this study, because only de-identified secondary data were used. This is a commercial database and the datasets were accessed through a licence with IBM.

\section{Study Design and Population}

The EXPERT study was designed to compare outcomes before and after treatment switch (Fig. 1). The study period began on 1 January 2018, with data cutoff on 30 April 2020. The index date, defined as the date of treatment switch, was required to be at least 90 days before data extraction.

Records from eligible patients in the database were identified using Systematized Nomenclature of Medicine-Clinical Terms (SNOMED CT) codes (SNOMED International, London, UK) [17]. For inclusion, adults ( $\geq 18$ years old) in the database required a diagnosis code for T2D; those with a code for type 1 diabetes or gestational diabetes were excluded. Treatment switchers were identified as patients with records of at least one prescription for injectable semaglutide, and a prescription for any other GLP-1 RA in the 365 days before the earliest semaglutide prescription (baseline period). Patients whose records showed concomitant prescriptions for more than one GLP-1 RA at the time of the earliest semaglutide prescription were excluded, as were patients who received oral semaglutide.

\section{Outcomes}

The primary outcome in our analysis was change in HbA1c from baseline, and the secondary outcome was weight change from baseline. To examine the impact of switching from another GLP-1 RA to semaglutide in both the short term and the medium term, outcomes were assessed at 180 days (6 months) postswitch and also at 365 days (12 months) postswitch. The 6-month and 12-month cohorts were treated independently, so that any given individual could be included in either cohort, or in both, provided they had data available at the relevant time points. Separate HbA1c analyses were performed in a subgroup with baseline HbA1c $>7 \%$ and a subgroup with baseline HbA1c $>9 \%$, and weight reduction was assessed in subgroups with baseline body mass index $\left(\right.$ BMI) $>30 \mathrm{~kg} / \mathrm{m}^{2}$ and $>35 \mathrm{~kg} / \mathrm{m}^{2}$. 


\section{Secondary use of data}
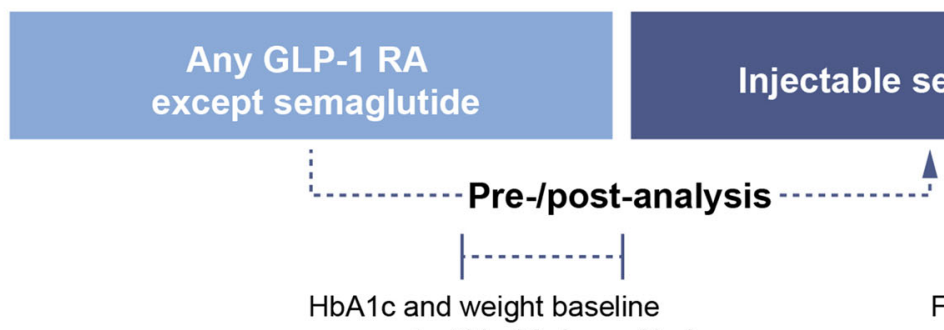

Injectable semaglutide

measurement within 90 days of index

Follow-up measurement within \pm 90 days of 180 and 365 days post-index

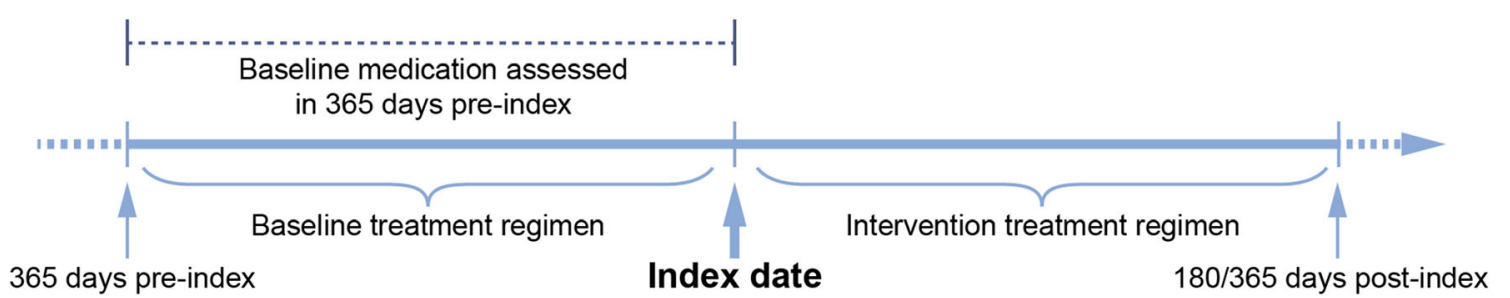

Fig. 1 Study design. HbAlc glycated haemoglobin, GLP-1 RA glucagon-like peptide-1 receptor agonist

For inclusion, patients required at least one HbA1c or weight measurement in the 90 days before the index date (baseline measurement) and a corresponding measurement at 180 days and/or 365 days after the index date (follow-up measurement; see Fig. 1). Follow-up measurements taken during the 90 days on either side of these post-index dates were valid, with the closest measurement to $180 / 365$ days post-index used as the follow-up value if multiple measurements were available. Patients with valid HbA1c measurements and those with valid weight measurements were treated as separate cohorts, and the data were analysed independently. There was no control group in the analysis; HbA1c and weight measurements before treatment switch (baseline) were compared with those after switch (follow-up).

\section{Statistical Analyses}

Mean HbA1c and weight changes from baseline were estimated using an analysis of covariance (ANCOVA) model. In the full model, baseline characteristics captured in the 365-day pre-index period were included as explanatory variables. These variables, which were selected because they are likely to affect treatment outcomes, encompassed both demographic factors (region, sex, age at index date) and clinical history (baseline HbA1c, baseline weight, CVD in the past 365 day [coronary heart disease, cerebrovascular disease, peripheral vascular disease or heart failure], Charlson-Deyo risk index score), as well as index year, insurance type and previous receipt of oral antidiabetic medications. Time from baseline assessments to index date and time from baseline assessments to index date squared were both included in the model to control for nonlinearity in effect based on time. The statistical significance of each variable in the model differed depending on model formulation; consequently, the full model including all explanatory variables was used for all outcomes, for consistency and easy comparison of results.

A minimal model was used for analyses in which there were insufficient numbers of eligible patients to allow use of the full model (see "Exploratory Analyses: Impact of Baseline BMI, Demaglutide Dose, Previous Treatment, Sex and Age"). This was an intercept-only model that corresponded to simple descriptive statistics and did not include any explanatory variables. 


\section{Sensitivity Analysis: Requirement for at Least Two Prescriptions for Baseline GLP-1 RA}

Prescription data reflect which medications are prescribed, but such prescriptions are not always collected and then used by the individual. For this study, EHR data were linked only to prescription information and not to claims data regarding prescription fills. Therefore, we performed an analysis in subgroups of patients with at least two prescriptions for their baseline GLP-1 RA treatment because this suggested that the first prescription had been collected. Some prescriptions, however, include several fills, meaning that this approach is likely to have excluded some patients who received their GLP1 RA throughout the baseline period. Consequently, the results of this more conservative analysis were compared with our main results as a sensitivity analysis.

\section{Exploratory Analyses: Impact of Baseline BMI, Demaglutide Dose, Previous Treatment, Sex and Age}

In a separate analysis, we compared the changes in HbA1c after switching to semaglutide in patients with normal weight (BMI $<25 \mathrm{~kg} / \mathrm{m}^{2}$ ) at baseline and those with higher baseline weight. We also compared a subgroup of patients with obesity $\left(\mathrm{BMI} \geq 30 \mathrm{~kg} / \mathrm{m}^{2}\right)$ at baseline with those whose BMI was lower. Furthermore, both HbA1c and weight changes from baseline were compared in subgroups who received semaglutide $0.25 \mathrm{mg}$ or $0.5 \mathrm{mg}$ upon switching treatments and in those who initially received the $1 \mathrm{mg}$ dose. We also examined whether the baseline GLP-1 RA product received, or concomitant use of insulin or sodium-glucose co-transporter-2 inhibitors (SGLT-2is), affected these outcomes. Further subgroup analyses were performed to compare outcomes for women and men, and for patients aged younger than 65 years and those aged 65 years or older.

To test statistically whether patients in subgroups defined by baseline BMI, semaglutide dose, baseline GLP-1 RA or previous treatment were significantly different from each other in terms of HbA1c and weight change, each subgroup variable was included in the ANCOVA model as an additional factor. Subgroup variables were added to the full model or the minimal model (for the SGLT-2is analysis), and tested one at a time. For variables with more than two subgroups, such as previous GLP-1 RA, a joint test into the effect across subgroups was conducted. Results were reported as mean $\mathrm{HbA1c}$ or weight change from baseline for each subgroup, with differences between subgroups expressed as $P$ values.

\section{RESULTS}

\section{Study Population and Cohorts}

A total of 6649 patients with T2D, no type 1 diabetes or gestational diabetes and at least one prescription for injectable semaglutide were identified in the database. Of these, 6254 were 18 years of age or older and did not have concomitant prescriptions for more than one GLP-1 RA at the time of first semaglutide prescription; 5641 individuals met all of the above criteria and had a first prescription for semaglutide at least 90 days before the cutoff date for data extraction. Figure 2 shows the numbers of patients in the HbA1c and weight cohorts with data at 6 months and 12 months, and in the subgroups with at least two prescriptions for baseline GLP-1 RA.

\section{Baseline Characteristics}

Baseline characteristics for the HbA1c $(n=710)$ and weight $(n=921)$ cohorts with data at 6 months are shown in Table 1 . The mean age was 58.9 years (standard deviation [SD] 10.8) in the HbA1c cohort and 58.5 years (SD 11.0) in the weight cohort. In the HbA1c cohort, $45.2 \%$ of patients were men; this percentage was $43.1 \%$ in the weight cohort. The mean HbA1c was $8.0 \%$ (SD 1.6) and 8.1\% (SD 1.7) in the two cohorts, respectively, and approximately $30 \%$ of patients in each cohort had HbA1c $<7 \%$ at baseline. The mean weight was $107.6 \mathrm{~kg}$ (SD 


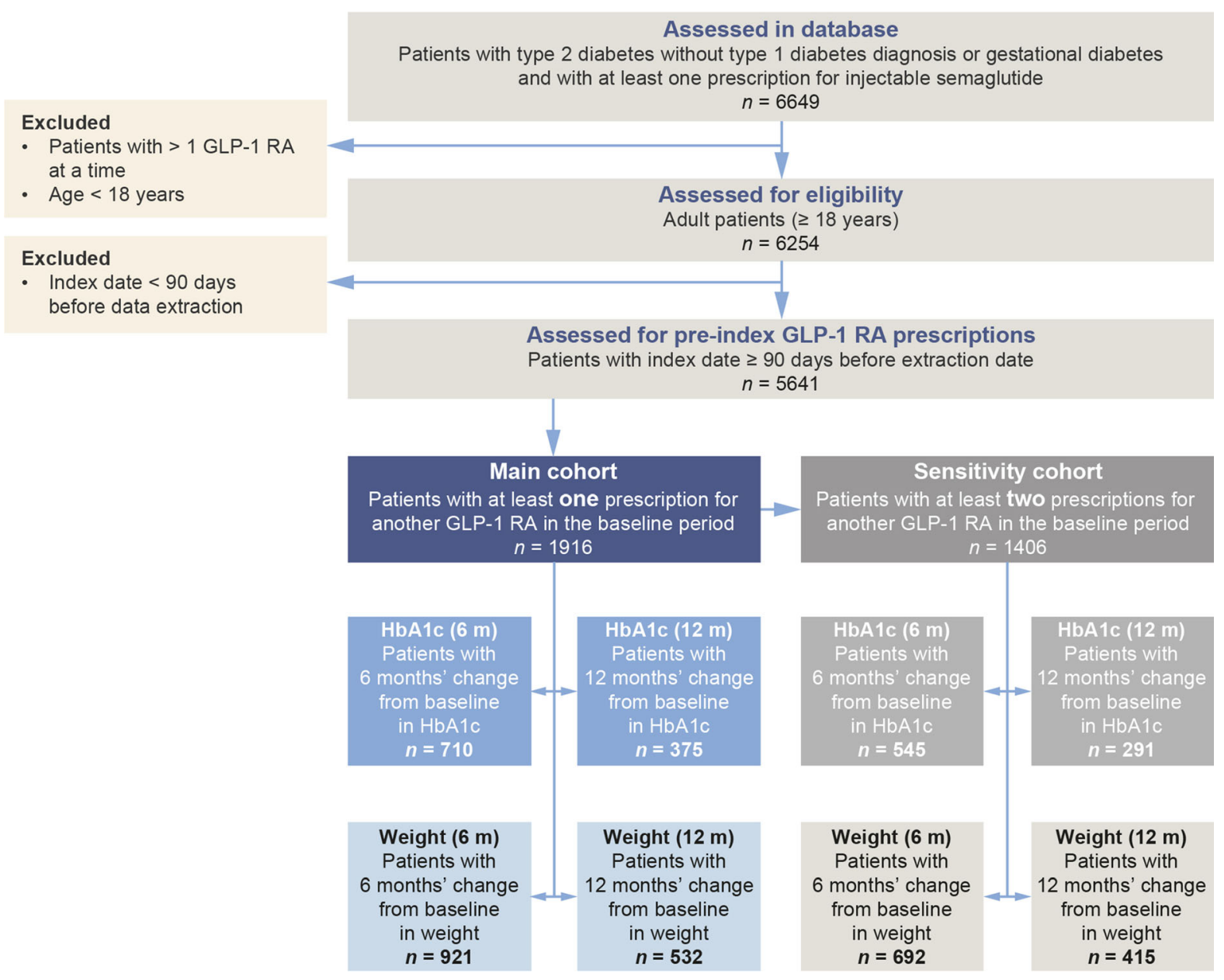

Fig. 2 Attrition diagram and cohort sizes for main HbAlc and weight analyses, and sensitivity analyses. HbAlc glycated haemoglobin, GLP-1 RA glucagon-like peptide-1 receptor agonist

26.1) and $107.1 \mathrm{~kg}$ (SD 25.9) in the two cohorts, respectively, and the mean BMI was $37.0 \mathrm{~kg} / \mathrm{m}^{2}$ (SD 8.1 ) and $36.9 \mathrm{~kg} / \mathrm{m}^{2}$ (SD 8.1), respectively. In each cohort, $2 \%$ of patients were of normal weight (BMI $<25 \mathrm{~kg} / \mathrm{m}^{2}$ ) and approximately $80 \%$ had obesity $\left(\right.$ BMI $\geq 30 \mathrm{~kg} / \mathrm{m}^{2}$ ).

The most common baseline GLP-1 RA was liraglutide (HbA1c cohort 47.5\%; weight cohort 49.8\%), followed by dulaglutide (HbA1c cohort $39.2 \%$; weight cohort $38.8 \%$ ) and once-weekly exenatide (HbA1c cohort 18.2\%; weight cohort 15.6\%; Table 1).

There were no major differences in baseline characteristics or baseline medication between the cohorts with data at 6 months and those with data at 12 months (Table 1). Baseline characteristics were also similar for the 6-month and 12-month cohorts with at least two prescriptions for baseline GLP-1 RA (sensitivity analyses; Table 2).

\section{Change in HbA1c From Baseline}

Following switching to injectable semaglutide, there were significant reductions in $\mathrm{HbA1c}$ from baseline to 6 months in the full cohort and in the two subgroups with HbA1c above target levels (Fig. 3a). The magnitude of change in HbA1c increased with baseline HbA1c, ranging from $-0.7 \%(95 \%$ confidence interval $[\mathrm{CI}]$ $-0.8,-0.6)$ in the full cohort to $-1.0 \%(95 \%$ CI $-1.2,-0.8)$ in those with baseline HbA1c > $7 \%$ and $-1.9 \%(95 \% \mathrm{CI}-2.3,-1.5)$ in those 
Table 1 Baseline characteristics for the HbAlc and weight cohorts with data at 6 and 12 months

\begin{tabular}{|c|c|c|c|c|}
\hline \multirow[t]{2}{*}{ Follow-up } & \multicolumn{2}{|l|}{6 months } & \multicolumn{2}{|l|}{12 months } \\
\hline & $\begin{array}{l}\text { HbAlc cohort } \\
n=710\end{array}$ & $\begin{array}{l}\text { Weight cohort } \\
n=921\end{array}$ & $\begin{array}{l}\text { HbA1c cohort } \\
n=375\end{array}$ & $\begin{array}{l}\text { Weight cohort } \\
n=532\end{array}$ \\
\hline Age, years & $58.9(10.8)$ & $58.5(11.0)$ & $58.7(10.2)$ & $59.1(10.5)$ \\
\hline Sex, men/women, \% & $45.2 / 54.8$ & $43.1 / 56.9$ & $44.5 / 55.5$ & $41.7 / 58.3$ \\
\hline Weight, kg & $107.6(26.1)$ & $107.1(25.9)$ & $105.5(26.1)$ & $105.7(26.0)$ \\
\hline BMI, $\mathrm{kg} / \mathrm{m}^{2}$ & $37.0(8.1)$ & $36.9(8.1)$ & $36.2(7.9)$ & $36.6(8.2)$ \\
\hline HbAlc, \% & $8.0(1.6)$ & $8.1(1.7)$ & $7.9(1.7)$ & $8.0(1.7)$ \\
\hline Charlson-Deyo risk index score $[20,21]$ & $2.6(2.0)$ & $2.8(2.1)$ & $2.5(1.9)$ & $2.7(2.0)$ \\
\hline $\begin{array}{l}\text { CVD ( } 12 \text { months before/any time before } \\
\text { index date), } \%\end{array}$ & $19.7 / 31.8$ & $22.4 / 35.5$ & $16.3 / 26.4$ & $21.1 / 34.0$ \\
\hline \multicolumn{5}{|l|}{ Baseline GLP-1 RA treatment, $n(\%)$} \\
\hline Liraglutide & $337(47.5)$ & $459(49.8)$ & $166(44.3)$ & $266(50.0)$ \\
\hline Dulaglutide & $278(39.2)$ & $357(38.8)$ & $156(41.6)$ & $197(37.0)$ \\
\hline Exenatide once weekly & $129(18.2)$ & $144(15.6)$ & $81(21.6)$ & $98(18.4)$ \\
\hline Albiglutide & $11(1.5)$ & $16(1.7)$ & $8(2.1)$ & $15(2.8)$ \\
\hline Lixisenatide & $15(2.1)$ & $23(2.5)$ & $9(2.4)$ & $9(1.7)$ \\
\hline Exenatide twice daily & $4(0.6)$ & $8(1.1)$ & $2(0.5)$ & $6(1.1)$ \\
\hline Exenatide, frequency not specified & $29(4.1)$ & $43(4.7)$ & $12(3.2)$ & $23(4.3)$ \\
\hline \multicolumn{5}{|l|}{ Starting dose of injectable semaglutide, $n$ (\%) } \\
\hline $1 \mathrm{mg}$ & $103(16.4)$ & $123(14.9)$ & $56(17.0)$ & $75(15.8)$ \\
\hline $0.25 \mathrm{mg} / 0.5 \mathrm{mg}$ & $524(83.6)$ & $702(85.1)$ & $274(83.0)$ & $401(84.2)$ \\
\hline \multicolumn{5}{|l|}{ Baseline medication, $n$ (\%) } \\
\hline Biguanides & $507(71.4)$ & $627(68.1)$ & $269(71.7)$ & $362(68.0)$ \\
\hline Sulphonylureas & $193(27.2)$ & $234(25.4)$ & $97(25.9)$ & $141(26.5)$ \\
\hline Thiazolidinediones & $102(14.4)$ & $104(11.3)$ & $52(13.9)$ & $68(12.8)$ \\
\hline DPP-4i & $114(16.1)$ & $145(15.7)$ & $66(17.6)$ & $82(15.4)$ \\
\hline SGLT-2i & $285(40.1)$ & $302(32.8)$ & $149(39.7)$ & $181(34.0)$ \\
\hline Combinations & $107(15.1)$ & $121(13.1)$ & $56(14.9)$ & $68(12.8)$ \\
\hline Long-acting insulin & $308(43.4)$ & $410(44.5)$ & $161(42.9)$ & $228(42.9)$ \\
\hline Fast-acting insulin & $136(19.2)$ & $201(21.8)$ & $69(18.4)$ & $117(22.0)$ \\
\hline
\end{tabular}


Table 1 continued

\begin{tabular}{|c|c|c|c|c|}
\hline \multirow[t]{2}{*}{ Follow-up } & \multicolumn{2}{|l|}{6 months } & \multicolumn{2}{|l|}{12 months } \\
\hline & $\begin{array}{l}\text { HbA1c cohort } \\
n=710\end{array}$ & $\begin{array}{l}\text { Weight cohort } \\
n=921\end{array}$ & $\begin{array}{l}\text { HbAlc cohort } \\
n=375\end{array}$ & $\begin{array}{l}\text { Weight cohort } \\
n=532\end{array}$ \\
\hline Any type of insulin & $332(46.8)$ & $450(48.9)$ & $170(45.3)$ & $254(47.7)$ \\
\hline
\end{tabular}

$B M I$ body mass index, $C V D$ cardiovascular disease, DPP-4i dipeptidyl peptidase-4 inhibitor, GLP-1 RA glucagon-like peptide-1 receptor agonist, $H b A 1 c$ glycated haemoglobin, $S D$ standard deviation, $S G L T$ - $2 i$ sodium-glucose co-transporter-2 inhibitor. Data are means (SD) except where otherwise stated. The Charlson-Deyo risk index is used to predict 10-year survival in patients with multiple comorbidities. CVD included coronary heart disease, cerebrovascular disease, peripheral vascular disease and heart failure

with baseline HbA1c $>9 \%$ (all $P<0.0001$ for change from baseline). Similar results were noted at 12 months. Mean change from baseline in the full cohort was $-0.8 \%(95 \% \mathrm{CI}$ $-1.0,-0.5)$. In the subgroup with HbA1c $>$ $7 \%$ this reduction was $-1.1 \% \quad(95 \% \quad$ CI $-1.5,-0.8)$, and in those with HbA1c $>9 \%$ it was $-2.2 \% \quad(95 \% \quad$ CI $\quad-3.0,-1.5) \quad$ (all $P<0.0001$ ).

Reductions in HbA1c from baseline for patients with at least two baseline GLP-1 RA prescriptions were similar to those observed in the main analysis (Fig. 4a). At 6 months, HbA1c reductions were $-0.6 \% \quad(95 \% \quad \mathrm{CI}$ $-0.8,-0.5),-0.9 \%(95 \%$ CI $-1.1,-0.7)$ and $-1.7 \% \quad(95 \% \quad$ CI $-2.2,-1.2) \quad$ (all $P<0.0001)$ across the full HbA1c cohort and the two subgroups. At 12 months, reductions were also similar to those observed in the main analysis. In the full cohort, the reduction was $-0.7 \%(95 \% \mathrm{CI}-1.0,-0.4 ; P<0.0001)$, and in the two subgroups it was $-1.1 \%(95 \%$ CI $-1.4,-0.7 ; P<0.0001)$ and $-2.1 \%(95 \%$ CI $-2.9,-1.2 ; P=0.0007)$, respectively.

\section{Change in Weight From Baseline}

There were significant $(P<0.0001)$ weight reductions from baseline to 6 months in the full weight cohort $(-2.1 \mathrm{~kg}$; 95\% CI $-2.6,-1.6)$ and in the subgroups of patients with BMI > $30 \mathrm{~kg} / \mathrm{m}^{2}(-2.3 \mathrm{~kg} ; 95 \% \mathrm{CI}-2.9,-1.7)$ and $>$ $35 \mathrm{~kg} / \mathrm{m}^{2} \quad(-2.4 \mathrm{~kg} ; \quad 95 \% \quad$ CI $-3.1,-1.7$; Fig. 3b). Weight loss was more pronounced at 12 months than at 6 months, with reductions of $-2.8 \mathrm{~kg}(95 \% \mathrm{CI}-3.9,-1.8)$ in the full cohort, $-3.3 \mathrm{~kg}(95 \% \mathrm{CI}-4.6,-2.1)$ in those with baseline BMI $>30 \mathrm{~kg} / \mathrm{m}^{2}$ and $-4.3 \mathrm{~kg}$ $(95 \%$ CI $-5.9,-2.8)$ in those with baseline BMI $>35 \mathrm{~kg} / \mathrm{m}^{2}$.

The sensitivity analysis with at least two baseline GLP-1 RA prescriptions supported these results (Fig. 4b). There was significant $(P<0.0001)$ weight reduction at 6 months in the full cohort and both subgroups $(-2.2 \mathrm{~kg}$ [95\% CI - 2.7, - 1.6], - $2.3 \mathrm{~kg}[-2.9,-1.7]$ and $-2.2 \mathrm{~kg}[-2.9,-1.4]$, respectively), and larger reductions at 12 months $(-3.1 \mathrm{~kg}[95 \%$ CI $-4.1,-2.0],-3.7 \mathrm{~kg} \quad[-5.0,-2.4]$ and $-4.3 \mathrm{~kg}[-6.0,-2.5]$, respectively).

\section{Impact of Baseline BMI on Change in $\mathrm{HbA1c}$}

HbA1c improved by $1.3 \%$ from baseline to 6 months in a subgroup of patients with baseline BMI $<25 \mathrm{~kg} / \mathrm{m}^{2}$, a reduction that was not significantly different from that observed in patients with $\mathrm{BMI} \geq 25 \mathrm{~kg} / \mathrm{m}^{2}$, who displayed a $0.7 \%$ reduction $(P=0.17$; Fig. 5). Similar reductions in $\mathrm{HbA1c}$ were also observed in patients with baseline BMI of either $<30 \mathrm{~kg} / \mathrm{m}^{2}$ or $\geq 30 \mathrm{~kg} / \mathrm{m}^{2}$ (both $-0.7 \% ; P=0.82$; Fig. 5 ). These patterns were replicated in the data for 12 months (Fig. 6). 
Table 2 Baseline characteristics for the HbAlc and weight cohorts with data at 6 and 12 months and at least two prescriptions for baseline GLP-1 RA

\begin{tabular}{|c|c|c|c|c|}
\hline \multirow[t]{2}{*}{ Follow-up } & \multicolumn{2}{|l|}{6 months } & \multicolumn{2}{|l|}{12 months } \\
\hline & $\begin{array}{l}\text { HbA1c cohort } \\
n=545\end{array}$ & $\begin{array}{l}\text { Weight cohort } \\
n=692\end{array}$ & $\begin{array}{l}\text { HbA1c cohort } \\
n=291\end{array}$ & $\begin{array}{l}\text { Weight cohort } \\
n=415\end{array}$ \\
\hline Age, years & $58.7(10.3)$ & $58.5(10.5)$ & $58.6(9.5)$ & $59.2(9.6)$ \\
\hline Sex, men/women, \% & $42.6 / 57.4$ & $40.9 / 59.1$ & $41.9 / 58.1$ & $40.7 / 59.3$ \\
\hline Weight, kg & $106.6(26.2)$ & $106.7(26.1)$ & $103.7(25.3)$ & $104.9(25.9)$ \\
\hline BMI, $\mathrm{kg} / \mathrm{m}^{2}$ & $36.8(8.3)$ & $36.8(8.3)$ & $35.7(7.8)$ & $36.4(8.4)$ \\
\hline HbAlc, \% & $8.0(1.6)$ & $8.1(1.7)$ & $7.9(1.7)$ & $8.0(1.7)$ \\
\hline Charlson-Deyo risk index score $[20,21]$ & $2.5(1.9)$ & $2.6(2.1)$ & $2.3(1.8)$ & $2.6(2.0)$ \\
\hline $\begin{array}{l}\text { CVD (12 months before/any time before } \\
\text { index date), } \%\end{array}$ & $16.1 / 29.4$ & $19.2 / 33.1$ & $13.7 / 23.7$ & $18.8 / 31.6$ \\
\hline \multicolumn{5}{|l|}{ Baseline GLP-1 RA treatment, $n$ (\%) } \\
\hline Liraglutide & $249(45.7)$ & $341(49.3)$ & $120(41.2)$ & $198(47.7)$ \\
\hline Dulaglutide & $205(37.6)$ & $251(36.3)$ & $118(40.5)$ & $139(33.5)$ \\
\hline Exenatide once weekly & $110(20.2)$ & $119(17.2)$ & $72(24.7)$ & $88(21.2)$ \\
\hline Albiglutide & $9(1.7)$ & $13(1.9)$ & $7(2.4)$ & $13(3.1)$ \\
\hline Lixisenatide & $11(2.0)$ & $17(2.5)$ & $7(2.4)$ & $8(1.9)$ \\
\hline Exenatide twice daily & $3(0.6)$ & $6(0.9)$ & $1(0.3)$ & $5(1.2)$ \\
\hline Exenatide, frequency not specified & $14(2.6)$ & $19(2.7)$ & $5(1.7)$ & $11(2.7)$ \\
\hline \multicolumn{5}{|l|}{ Starting dose of injectable semaglutide, $n$ (\%) } \\
\hline $1 \mathrm{mg}$ & $82(16.5)$ & $95(15.0)$ & $43(16.2)$ & $60(15.8)$ \\
\hline $0.25 \mathrm{mg} / 0.5 \mathrm{mg}$ & $415(83.5)$ & $539(85.0)$ & $223(83.8)$ & $320(84.2)$ \\
\hline \multicolumn{5}{|l|}{ Baseline medication, $n(\%)$} \\
\hline Biguanides & $326(59.8)$ & $384(55.5)$ & $177(60.8)$ & $235(56.6)$ \\
\hline Sulphonylureas & $117(21.5)$ & $139(20.1)$ & $55(18.9)$ & $87(21.0)$ \\
\hline Thiazolidinediones & $83(15.2)$ & $83(12.0)$ & $41(14.1)$ & $55(13.3)$ \\
\hline DPP-4i & $67(12.3)$ & $78(11.3)$ & $39(13.4)$ & $46(11.1)$ \\
\hline SGLT-2i & $208(38.2)$ & $211(30.5)$ & $107(36.8)$ & $129(31.1)$ \\
\hline Combinations & $90(16.5)$ & $95(13.7)$ & $46(15.8)$ & $54(13.0)$ \\
\hline Long-acting insulin & $208(38.2)$ & $271(39.2)$ & $110(37.8)$ & $153(36.9)$ \\
\hline Fast-acting insulin & $75(13.8)$ & $114(16.5)$ & $36(12.4)$ & $64(15.4)$ \\
\hline
\end{tabular}


Table 2 continued

\begin{tabular}{llllll}
\hline Follow-up & $\mathbf{6}$ months & & & $\mathbf{1 2}$ months & \\
\cline { 2 - 3 } & $\begin{array}{l}\text { HbA1c cohort } \\
\boldsymbol{n}=\mathbf{5 4 5}\end{array}$ & $\begin{array}{l}\text { Weight cohort } \\
\boldsymbol{n}=\mathbf{6 9 2}\end{array}$ & $\begin{array}{l}\text { HbA1c cohort } \\
\boldsymbol{n}=\mathbf{2 9 1}\end{array}$ & $\begin{array}{l}\text { Weight cohort } \\
\boldsymbol{n}=\mathbf{4 1 5}\end{array}$ \\
\hline Any type of insulin & $224(41.1)$ & $300(43.4)$ & $118(40.5)$ & $174(41.9)$ \\
\hline
\end{tabular}

$B M I$ body mass index, $C V D$ cardiovascular disease, DPP-4i dipeptidyl peptidase-4 inhibitor, GLP-1 RA glucagon-like peptide-1 receptor agonist, HbAIc glycated haemoglobin, $S D$ standard deviation, $S G L T$-2i sodium-glucose co-transporter-2 inhibitor. Data are means (SD) except where otherwise stated. The Charlson-Deyo risk index is used to predict 10-year survival in patients with multiple comorbidities. CVD included coronary heart disease, cerebrovascular disease, peripheral vascular disease and heart failure

\section{Impact of Semaglutide Dose, Previous GLP-1 RA, Treatment History, Sex and Age}

Data are shown in Fig. 5 for both HbA1c and weight reductions from baseline to 6 months. There were no significant differences between patients in the subgroup initiating with a $1 \mathrm{mg}$ dose of semaglutide (HbA1c $-0.6 \%$; weight $-2.6 \mathrm{~kg}$ ) and those in the subgroup who initiated with semaglutide $0.25 \mathrm{mg} / 0.5 \mathrm{mg}$ (HbA1c - 0.7\%; weight $-1.9 \mathrm{~kg}$ ).

The GLP-1 RA received before treatment switch did not have any impact on HbA1c reductions $\quad(-0.5,-0.7$ and $-0.6 \%$ for dulaglutide, liraglutide and any other GLP-1 RA, respectively; $P=0.63$ ) or weight reductions $(-2.8,-1.6$ and $-2.8 \mathrm{~kg}$, respectively; $P=0.12)$ at 6 months.

Patients who had not received insulin and those who had received insulin displayed no significant differences in terms of HbA1c reduction ( -0.8 vs. $-0.5 \% ; P=0.05$ ) or weight reduction $(-2.2$ vs. $-2.0 \mathrm{~kg} ; P=0.63)$ at 6 months. Similarly, receipt of SGLT-2i (no/yes; minimal model used) had no effect on HbA1c $(-0.6$ vs. $-0.4 \% ; \quad P=0.06)$ or weight (both $-1.9 \mathrm{~kg} ; P=0.97$ ) at this time point. There was no significant difference between HbA1c or weight reductions for women and those for men, and no differences between patients younger than 65 years and those aged 65 years or older (Electronic Supplementary Material [ESM] Table S1).

No significant differences between any of the subgroups were present in the patient cohorts with HbA1c and weight data at 12 months (Fig. 6; ESM Table S1).

\section{DISCUSSION}

In an effort to inform clinical decision-making at the point of treatment switch between GLP-1 RAs, we have examined the impact upon key endpoints of switching to injectable semaglutide from any other GLP-1 RA. We show that switching from any GLP-1 RA to semaglutide is associated with significant $\mathrm{HbA1c}$ reductions at 6 months, which appeared to be maintained at 12 months. Patients experienced significant weight loss by 6 months after treatment switch and had continued to lose weight by 12 months, an effect that was particularly pronounced in those with BMI $>35 \mathrm{~kg} / \mathrm{m}^{2}$. These results indicate that switching to injectable semaglutide from any other GLP-1 RA leads to improvement in both glycaemic control and weight, effects that are apparent after 12 months of treatment. We also showed that these results were independent of either insulin or SGLT-2i prescription during the baseline period, and also independent of the previous GLP-1 RA received. Furthermore, we showed that results were similar in patients who commenced treatment with a lower dose of semaglutide and those who received a $1 \mathrm{mg}$ dose at the time of switching. This result may be due to dose escalation between the switch and follow-up: the label for injectable semaglutide recommends titration from 0.25 to $0.5 \mathrm{mg}$ 
(A)

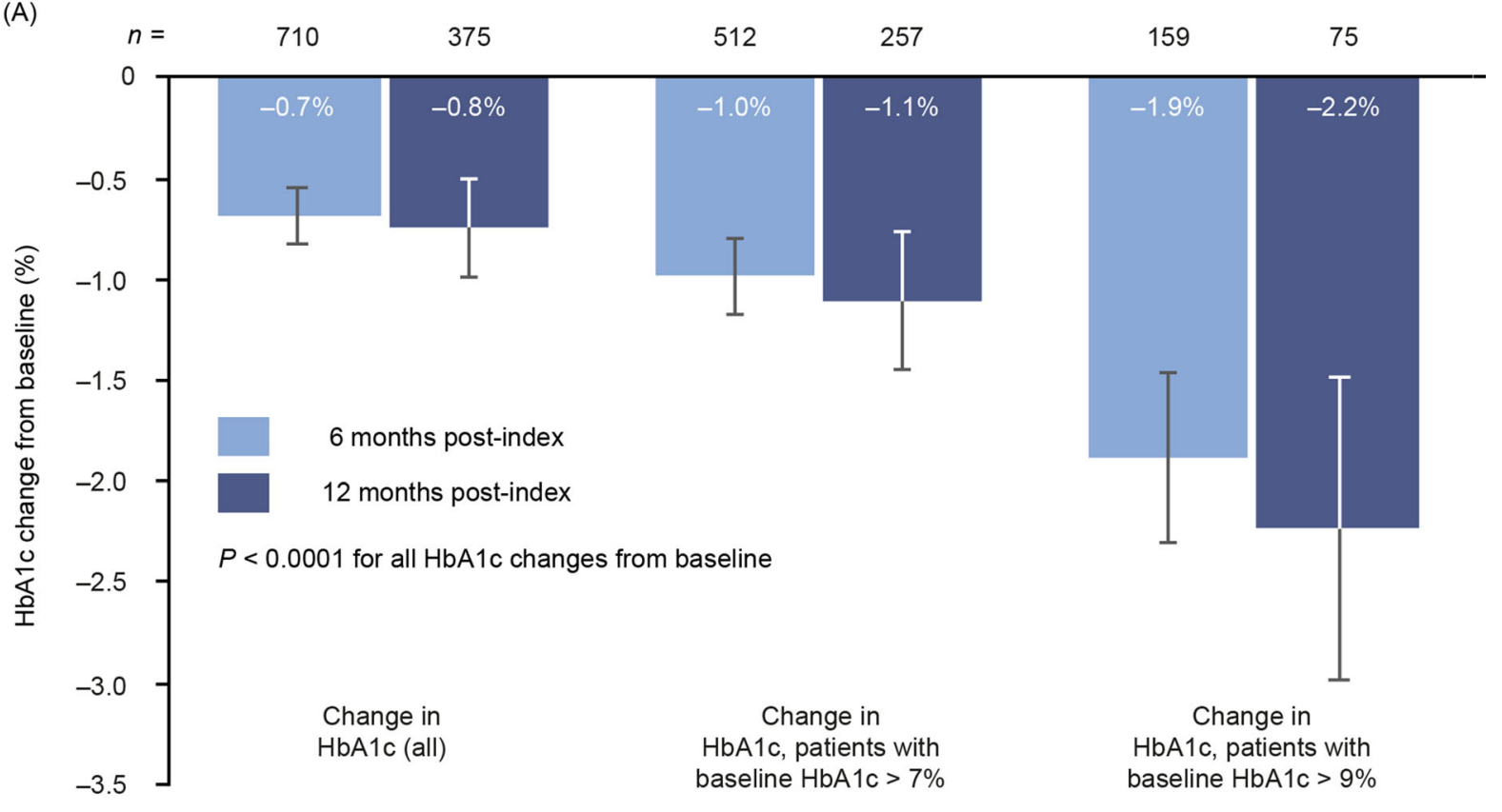

(B)

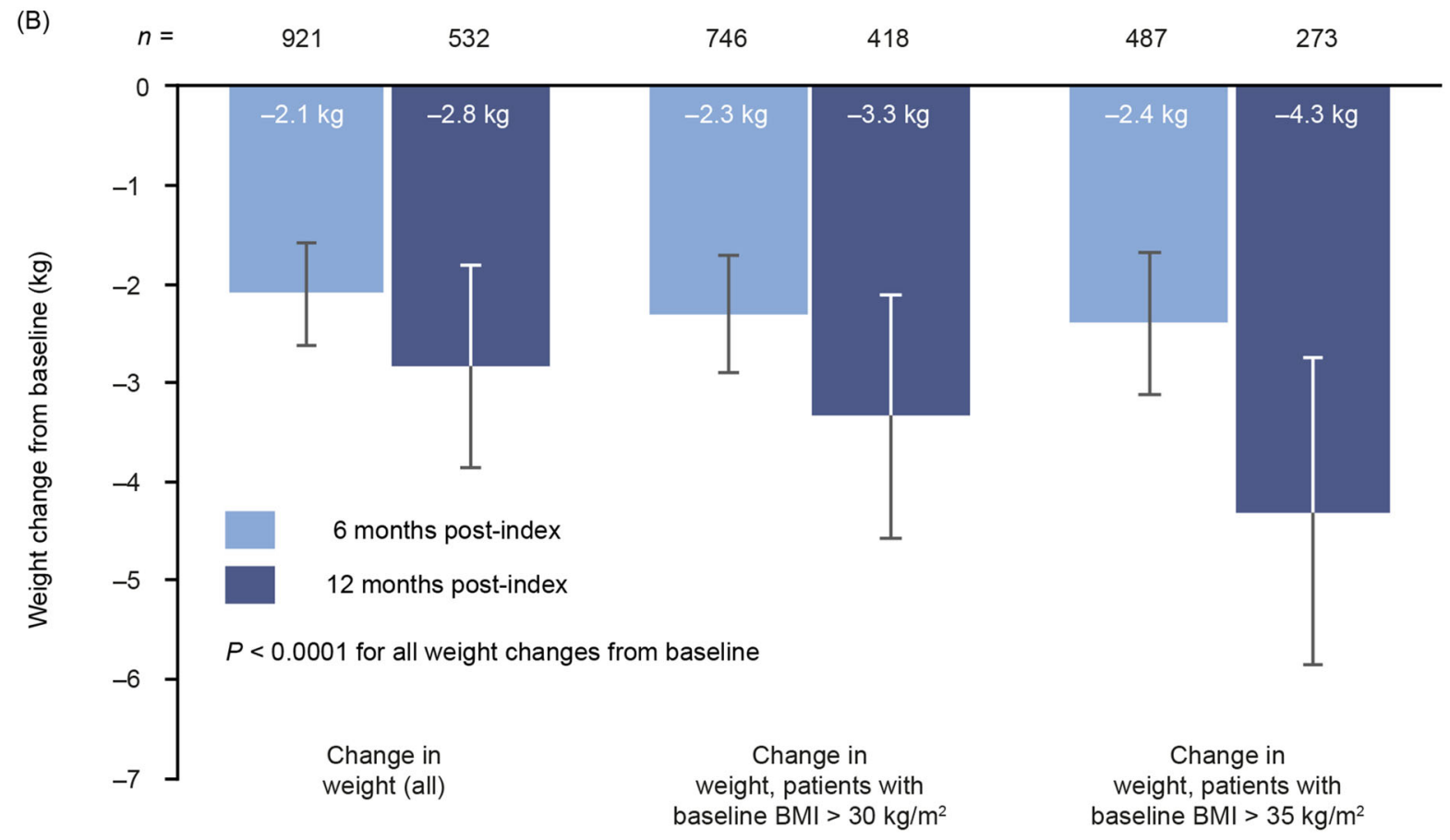

$487 \quad 273$

Fig. 3 Changes in HbAlc (a) and weight (b) from baseline to 6 and 12 months. BMI body mass index, $H b A 1 c$ glycated haemoglobin

4 weeks after treatment initiation, with the possibility of further titration to $1 \mathrm{mg}$ after another 4 weeks [4]. Additionally, patients initiating treatment with semaglutide $1 \mathrm{mg}$ may have received higher doses of their baseline GLP-1 RA, meaning that the improvements 
(A)

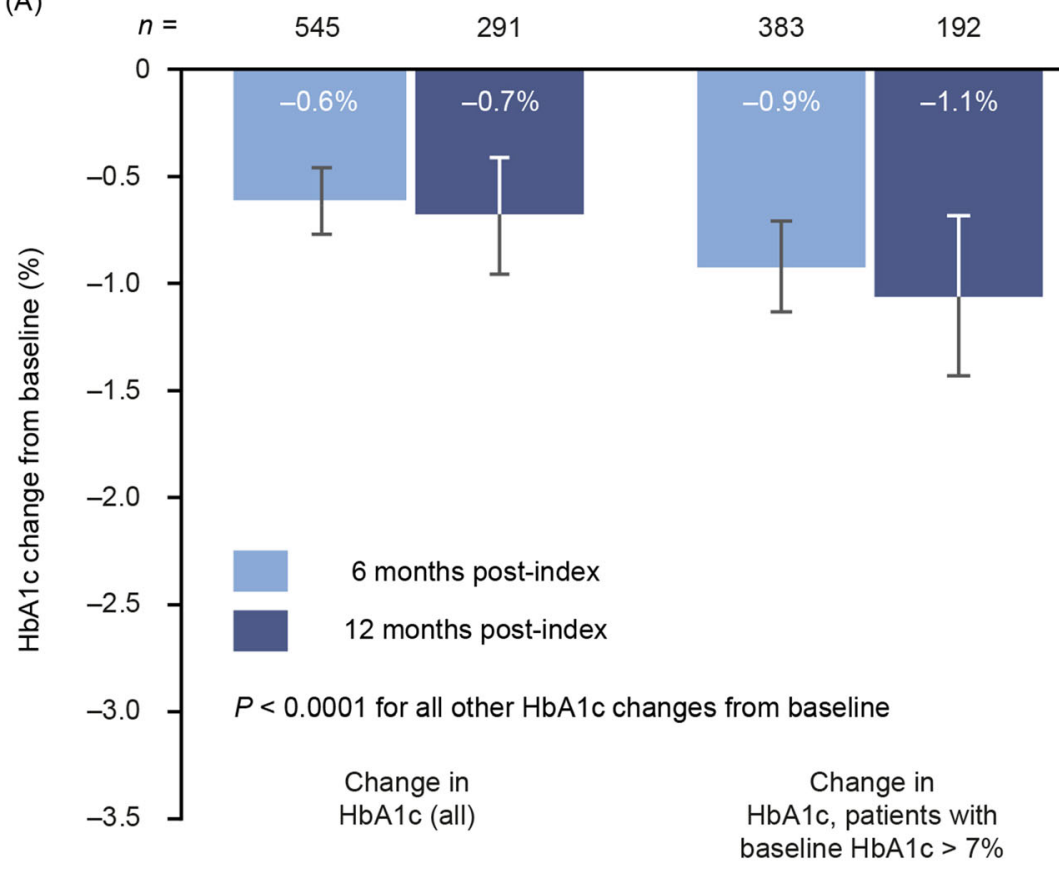

(B)

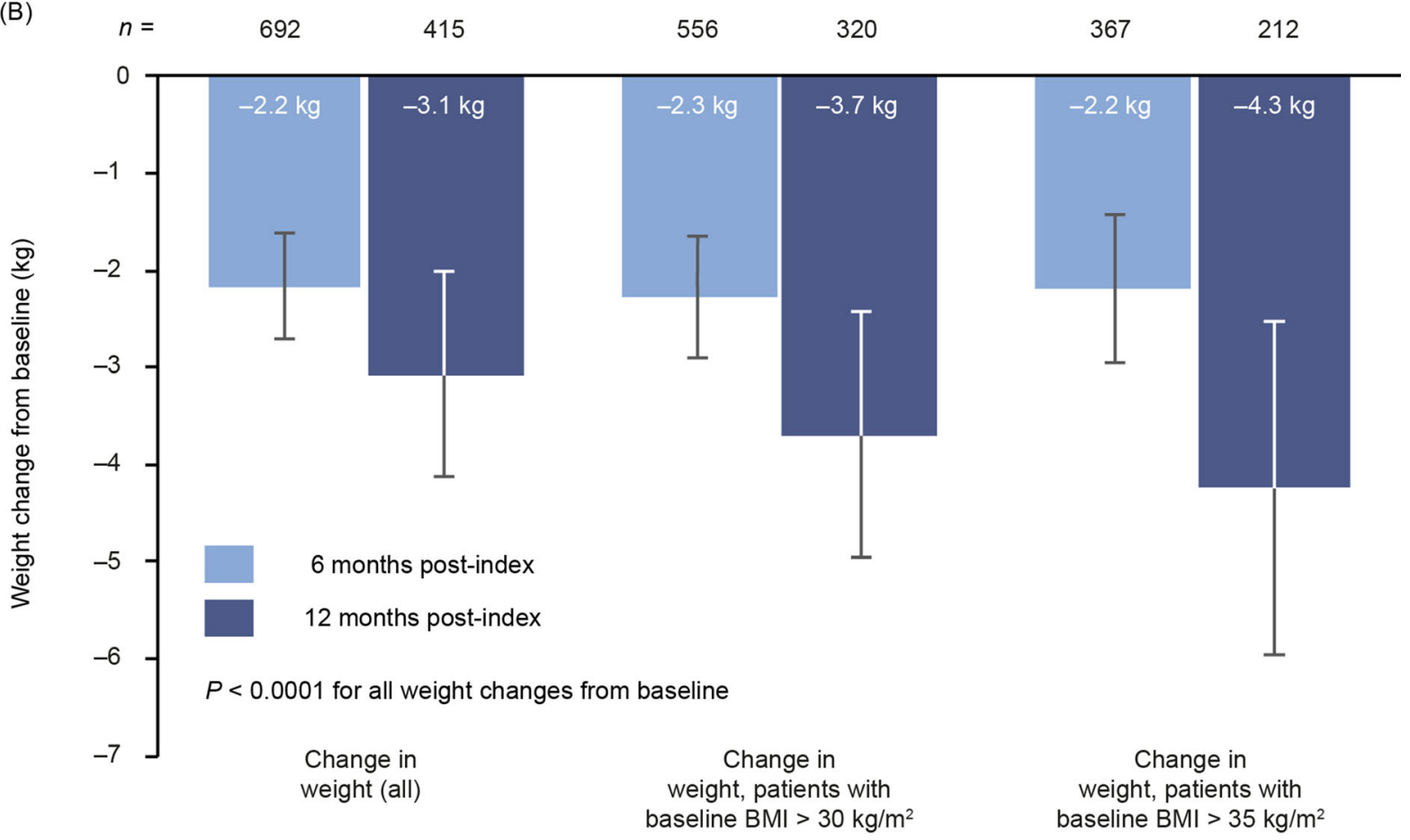

Fig. 4 Changes in HbAlc (a) and weight (b) from baseline to 6 and 12 months in the sensitivity analysis requiring at least two prescriptions for baseline GLP-1 RA.
$B M I$ body mass index, $G L P-1 R A$ glucagon-like peptide-1 receptor agonist, $H b A 1 c$ glycated haemoglobin

comparatively less pronounced in these 


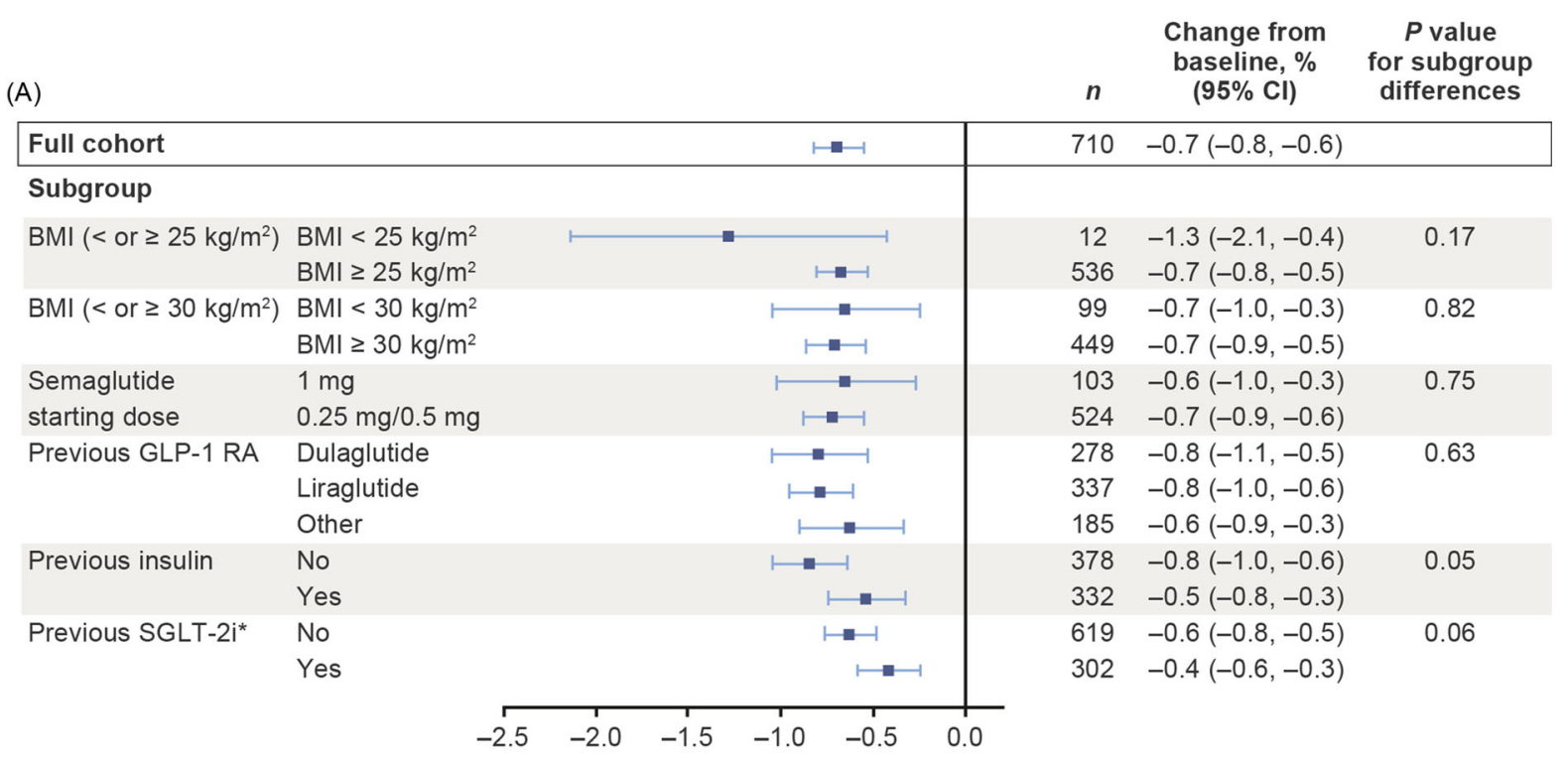

Change in $\mathrm{HbA} 1 \mathrm{c}$ from baseline to 6 months (\%)

(B)

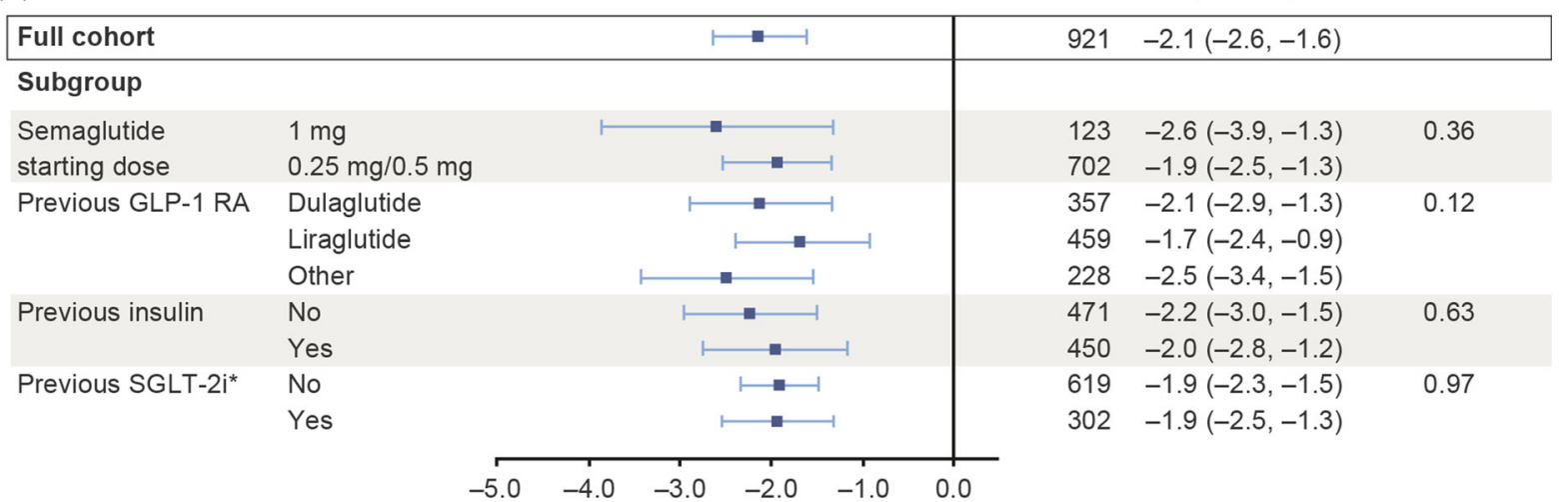

Change in weight from baseline to 6 months $(\mathrm{kg})$

Fig. 5 Changes in HbAlc (a) and weight (b) from baseline to 6 months in subgroups defined by baseline BMI, starting dose of semaglutide, baseline GLP-1 RA and previous treatment. Asterisk indicates that the minimal model was used owing to small available sample size. Changes from baseline in the full cohort using the minimal model were $-0.5 \%$ for $\mathrm{HbAlc}$ and $-1.9 \mathrm{~kg}$ for weight. Explanatory variables were: subgroup, region, sex, age at index date, baseline weight, baseline HbAlc, Charlson-Deyo risk index score, cardiovascular disease in the past year, index year, insurance type, previous receipt of oral antidiabetic medications, time from actual follow-up assessments to nominal follow-up time and time from actual follow-up assessments to nominal follow-up time squared. Estimated treatment effects and corresponding 95\% confidence intervals (95\% CIs) were based on all patients with at least one prescription of the specific GLP$1 \mathrm{RA}$ in the baseline period. When comparing subgroups by means of the $P$ value, patients with prescriptions for different types of GLP-1 RAs in the baseline period were excluded. BMI body mass index, $C I$ confidence interval, GLP-1 RA glucagon-like peptide-1 receptor agonist, $H b A 1 c$ glycated haemoglobin, $S G L T-2 i$ sodium-glucose co-transporter-2 inhibitor

\section{patients.}


(A)

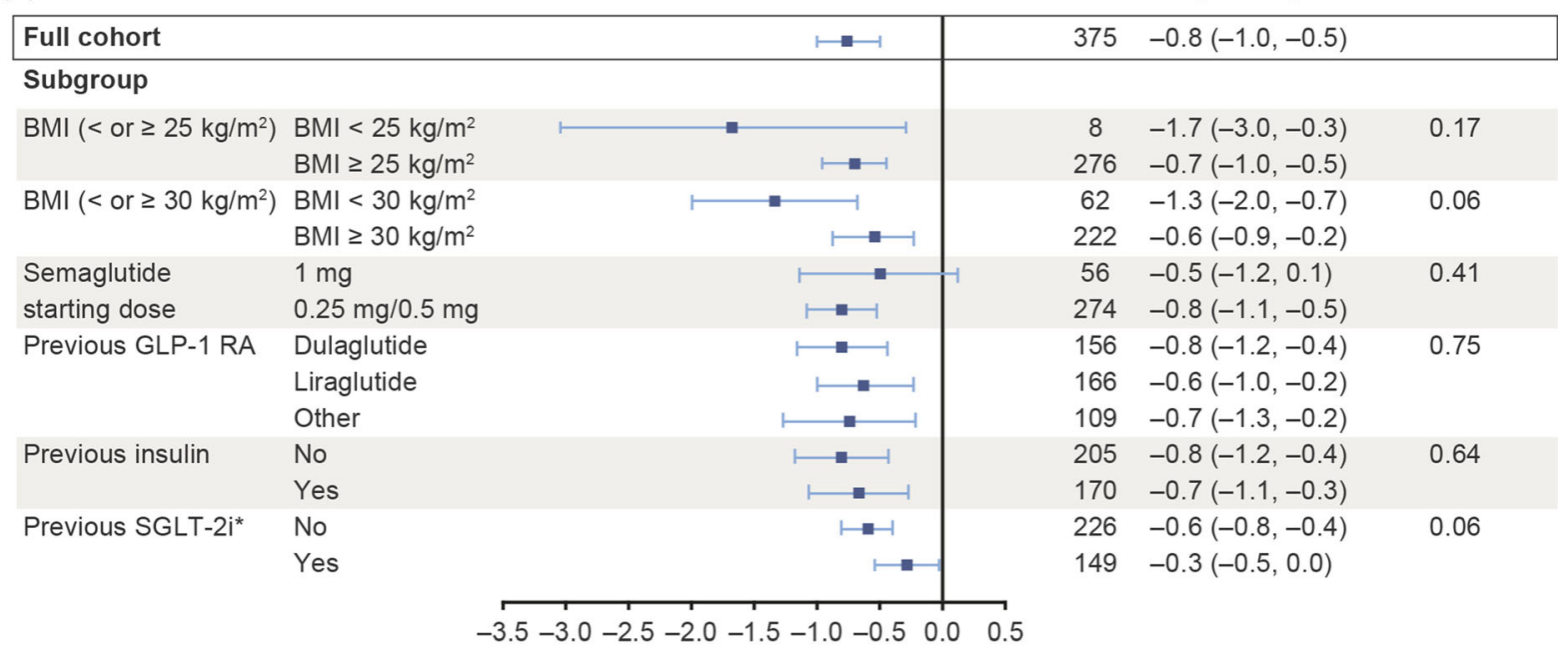

Change in $\mathrm{HbA} 1 \mathrm{c}$ from baseline to 12 months (\%)

(B)

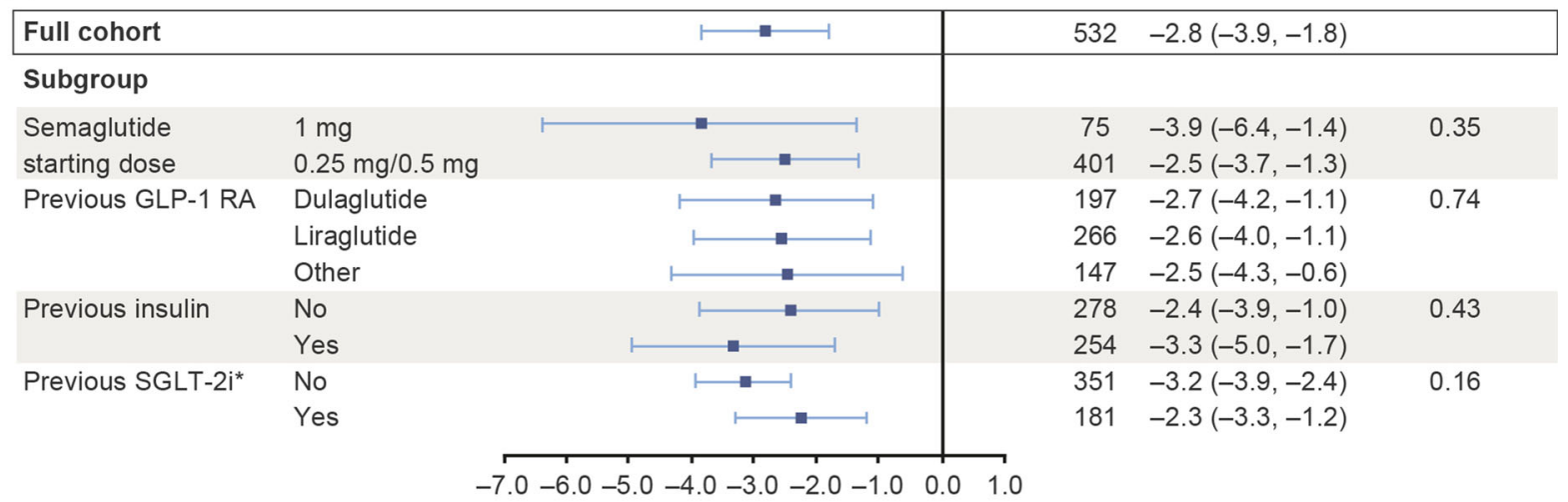

Change in weight from baseline to 12 months $(\mathbf{k g})$

Fig. 6 Changes in HbAlc (a) and weight (b) from baseline to 12 months in subgroups defined by baseline BMI, starting dose of semaglutide, baseline GLP-1 RA and previous treatment. Asterisk indicates that the minimal model was used owing to small available sample size. Changes from baseline in the full cohort using the minimal model were $-0.5 \%$ for HbAlc and $-2.9 \mathrm{~kg}$ for weight. Explanatory variables were subgroup, region, sex, age at index date, baseline weight, baseline HbAlc, Charlson-Deyo risk index score, cardiovascular disease in the past year, index year, insurance type, previous receipt of oral antidiabetic medications, time from actual follow-up assessments to nominal follow-up time and time from actual follow-up assessments to nominal follow-up time squared. Estimated treatment effects and corresponding 95\% CIs were based on all patients with at least one prescription of the specific GLP-1 RA in the baseline period. When comparing subgroups by means of the $P$ value, patients with prescriptions for different types of GLP-1 RAs in the baseline period were excluded. BMI body mass index, $C I$ confidence interval, GLP-1 RA glucagon-like peptide-1 receptor agonist, $H b A 1 c$ glycated haemoglobin, SGLT-2i sodium-glucose co-transporter-2 inhibitor 
The key strengths of our study are the large, comprehensive source of real-world data available and the robust study design. These allowed us to evaluate outcomes specifically in patients who switched treatment, addressing an important area in clinical practice that has not been investigated in RCTs. Although the SUSTAIN trial programme has provided evidence for the efficacy and safety of semaglutide [18], patients treated with GLP-1 RAs immediately before the study period were not included. Furthermore, the study populations in RCTs are not fully representative of patients receiving treatment for T2D in clinical practice. For example, the SUSTAIN trials included only patients with baseline HbA1c between 7 and 11\%; in our study, inclusion was not restricted by baseline HbA1c, and approximately $30 \%$ of those included had $\mathrm{HbA1c}<7 \%$ at baseline. To address the potential for bias in our analyses, we used models adjusted for all relevant baseline characteristics extracted from the data set. To maximize the number of eligible patients, we performed analyses in separate $\mathrm{HbA1c}$ and weight cohorts. These cohorts were similar in terms of demographic and key clinical factors, despite disparities in the available sample sizes, providing confidence that the separation of these analyses did not impose selection bias on our study.

The retrospective, observational nature of our study and the use of prescription data must be acknowledged as limitations because they meant that some relevant factors could not be captured and accounted for in our analyses. Data on duration of medication use, adherence, discontinuation and concomitant medications cannot be captured from prescriptions databases, and dosing data for liraglutide and dulaglutide were unavailable or incomplete, so it was not possible to determine whether patients were optimized on their baseline GLP-1 RA. Motivations for treatment switch cannot be determined retrospectively; therefore, although we have shown HbA1c and weight improvements in cohorts switching to semaglutide, these patients may have switched treatment for various reasons other than glycaemic control and weight loss.
To address any uncertainty surrounding whether patients had collected and then taken their prescribed medication, which is a major limitation of prescription data, we conducted a more stringent sensitivity analysis in subgroups of patients who had at least two prescriptions for their GLP-1 RA in the baseline period, suggesting that they had used their first prescription. The results of this analysis were in line with those for the full HbA1c and weight cohorts, supporting the key conclusions of our analysis. In future, once data are available on a larger number of patients switching treatments, the use of administrative claims data in similar analyses would help to increase confidence that the patients represented are those who have collected and adhered to treatment following switching. Our conclusions would also be strengthened by repeating our analysis with a control group, comparing patients who switched to semaglutide with those who remained on their index GLP-1 RA or who switched to a different GLP-1 RA, such as dulaglutide. Comparison with patients switching from semaglutide to another GLP-1 RA would also be valuable. Such comparative analyses require sufficient numbers of eligible patients to permit matching of treatment arms, as well as statistical adjustment to ensure unbiased comparisons; however, when these analyses are feasible, this approach would mitigate some of the biases inherent in a pre-/post-study design. By conducting direct comparisons of patients' experiences when switching GLP-1 RAs, more detailed information can be derived to support treatment choices in clinical practice.

Only a small number of previous studies have assessed the effects of switching to semaglutide from other GLP-1 RAs. A retrospective chart review of 164 patients with T2D who switched from either liraglutide or dulaglutide to semaglutide found that this switch was associated with reductions in HbA1c and weight at 3, 6 and 12 months after the switch [14]. Another recent, smaller, chart review focussed on 40 patients who switched from liraglutide to semaglutide. The minimum follow-up was 6 months; after this time, patients had experienced a mean $0.8 \%$ reduction in $\mathrm{HbA1c}$, with a mean weight loss of 
$4.6 \mathrm{~kg}$ [13]. Another study employed exposure-response modelling of data from the SUSTAIN trial programme to estimate the impact of switching from liraglutide, dulaglutide or exenatide extended-release to semaglutide. The average HbA1c reduction predicted by the model was $0.3-0.8 \%$, and the average weight loss was $2-4 \%$ [19]. The results of our analyses support and augment these published data to provide evidence of benefit upon treatment switch in various subgroups at different time points.

\section{CONCLUSIONS}

In conclusion, our results show that switching to injectable semaglutide from any other GLP-1 RA was associated with significant improvements in glycaemic control and weight. Improvements in glycaemic control 6 months after treatment initiation were sustained at 12 months, whereas maximum weight loss benefits required at least 12 months to become apparent. These results suggest that for patients already receiving a GLP-1 RA who require additional treatment for glycaemic control, a switch to semaglutide could provide HbA1c and weight benefits without the need for more frequent administration. Overall, our data provide real-world information to support decisionmaking in clinical practice in patients who have an indication to switch between GLP-1 RA products.

\section{ACKNOWLEDGEMENTS}

Funding. This study and the publication fees were funded by Novo Nordisk A/S.

Authorship. All named authors meet the International Committee of Medical Journal Editors (ICMJE) criteria for authorship for this article, take responsibility for the integrity of the work as a whole, and have given their approval for this version to be published.
Medical Writing Assistance. The authors acknowledge the medical writing assistance of Caroline Freeman of Oxford PharmaGenesis, Oxford, UK (funded by Novo Nordisk A/S).

Prior Presentation. An earlier iteration of these analyses was presented at the American Diabetes Association 80th Scientific Sessions: A Virtual Experience; 12-16 June 2020.

Disclosures. Ildiko Lingvay has performed consultancy for AstraZeneca, Boehringer Ingelheim Pharmaceuticals, Inc., Eli Lilly and Company, Intarcia Therapeutics, Janssen Pharmaceuticals, Inc., MannKind Corporation, Novo Nordisk A/S, Sanofi, TARGET PharmaSolutions and Valeritas, Inc. Andreas R. Kirk is an employee and shareholder of Novo Nordisk A/S. Søren Lophaven is employed as a consultant by Novo Nordisk A/S. Michael L. Wolden is an employee and shareholder of Novo Nordisk A/S. Jay H. Shubrook has participated in advisory panels for Bayer US, Eli Lilly and Company, Novo Nordisk Inc. and Sanofi US.

Compliance with Ethics Guidelines. Approval by an ethics committee was not required for this study because only de-identified secondary data were used. This is a commercial database and the datasets were accessed through a licence with IBM.

Data Availability. The datasets analysed during the current study are not publicly available because they are under licence from IBM. Aggregate data are available from the authors upon reasonable request.

Open Access. This article is licensed under a Creative Commons Attribution-NonCommercial 4.0 International License, which permits any non-commercial use, sharing, adaptation, distribution and reproduction in any medium or format, as long as you give appropriate credit to the original author(s) and the source, provide a link to the Creative Commons licence, and indicate if changes were made. The images or other third party material in this article are included in the article's Creative Commons licence, unless indicated otherwise in a credit 
line to the material. If material is not included in the article's Creative Commons licence and your intended use is not permitted by statutory regulation or exceeds the permitted use, you will need to obtain permission directly from the copyright holder. To view a copy of this licence, visit http://creativecommons.org/licenses/by$\mathrm{nc} / 4.0 /$.

\section{REFERENCES}

1. Tran KL, Park YI, Pandya S, et al. Overview of glucagon-like peptide-1 receptor agonists for the treatment of patients with type 2 diabetes. Am Health Drug Benefits. 2017;10:178-88.

2. American Diabetes Association. 9. Pharmacologic approaches to glycemic treatment: standards of medical care in diabetes-2020. Diabetes Care. 2020;43:S98-110.

3. Food and Drug Administration. BYETTA ${ }^{\circledR}$ (exenatide) injection. Highlights of prescribing information. Revised 10/2009. https://www.accessdata. fda.gov/drugsatfda_docs/label/2009/

021773s9s11s18s22s25lbl.pdf. Accessed 11 May 2020.

4. Food and Drug Administration. OZEMPIC (semaglutide) injection, for subcutaneous use. Revised 12/2017. https://www.accessdata.fda.gov/ drugsatfda_docs/label/2017/209637lbl.pdf. Accessed 28 Feb 2020.

5. Food and Drug Administration. FDA News Release. FDA approves first oral GLP-1 treatment for type 2 diabetes. 20 September 2019. https://www.fda.gov/ news-events/press-announcements/fda-approvesfirst-oral-glp-1-treatment-type-2-diabetes. Accessed 28 Feb 2020.

6. Gentilella R, Pechtner V, Corcos A, Consoli A. Glucagon-like peptide-1 receptor agonists in type 2 diabetes treatment: are they all the same? Diabetes Metab Res Rev. 2019;35:e3070.

7. Ahmann AJ, Capehorn M, Charpentier G, et al. Efficacy and safety of once-weekly semaglutide versus exenatide ER in subjects with type 2 diabetes (SUSTAIN 3): a 56-week, open-label, randomized clinical trial. Diabetes Care. 2018;41:258-66.

8. Pratley RE, Aroda VR, Lingvay I, et al. Semaglutide versus dulaglutide once weekly in patients with type 2 diabetes (SUSTAIN 7): a randomised, openlabel, phase $3 \mathrm{~b}$ trial. Lancet Diabetes Endocrinol. 2018;6:275-86.
9. Capehorn MS, Catarig AM, Furberg JK, et al. Efficacy and safety of once-weekly semaglutide $1.0 \mathrm{mg}$ vs once-daily liraglutide $1.2 \mathrm{mg}$ as add-on to $1-3$ oral antidiabetic drugs in subjects with type 2 diabetes (SUSTAIN 10). Diabetes Metab. 2019;46:100-9.

10. Divino V, Boye KS, Lebrec J, DeKoven M, Norrbacka K. GLP-1 RA treatment and dosing patterns among type 2 diabetes patients in six countries: a retrospective analysis of pharmacy claims data. Diabetes Ther. 2019;10:1067-88.

11. Almandoz JP, Lingvay I, Morales J, Campos C. Switching between glucagon-like peptide-1 receptor agonists: rationale and practical guidance. Clin Diabetes. 2020;38(4):390-402.

12. Chudleigh RA, Platts J, Bain SC. Comparative effectiveness of long-acting GLP-1 receptor agonists in type 2 diabetes: a short review on the emerging data. Diabetes Metab Syndr Obes. 2020;13:433-8.

13. Goncalves E, Bell DS. Efficacy of semaglutide versus liraglutide in clinical practice. Diabetes Metab. 2019;11:S1262-3636.

14. Jain AB, Kanters S, Khurana R, Kissock J, Severin N, Stafford S. Real world efficacy analysis of switch from liraglutide or dulaglutide to semaglutide in patients with type 2 diabetes mellitus: REALISE-DM Study. Poster presented at the International Diabetes Federation Congress, 2-6 December 2019, Busan, Korea. Poster number: OP 0073. Available from: https://www.morressier.com/article/realworld-efficacy-analysis-switch-liraglutidedulaglutide-semaglutide-type-2-dm-realisedmstudy/5d9b6229ea541d6ca8493880?

15. Tibaldi J, Hadley-Brown M, Liebl A, et al. A comparative effectiveness study of degludec and insulin glargine $300 \mathrm{U} / \mathrm{mL}$ in insulin-naive patients with type 2 diabetes. Diabetes Obes Metab. 2018;21: 1001-9.

16. IBM Watson Health. Data Sheet. IBM Explorys Electronic Health Record (EHR) Database. May 2019. Available from: https://www.ibm.com/ downloads/cas/6VQK0DLL. Accessed 08 Jun 2020.

17. SNOMED International. SNOMED CT Browser. https://browser.ihtsdotools.org/. Accessed 09 Jun 2020.

18. Medicine Matters Diabetes. A quick guide to the SUSTAIN trials. Updated September 2019. https:// diabetes.medicinematters.com/en-GB/semaglutide/ type-2-diabetes/a-quick-guide-to-the-sustain-trials/ 12206922. Accessed 17 Apr 2020.

19. Overgaard RV, Lindberg SO, Thielke D. Impact on HbA1c and body weight of switching from other GLP-1 receptor agonists to semaglutide: a model- 
based approach. Diabetes Obes Metab. 2019;21: 43-51.

20. Deyo RA, Cherkin DC, Ciol MA. Adapting a clinical comorbidity index for use with ICD-9-CM administrative databases. J Clin Epidemiol. 1992;45:613-9.

21. MDCalc. Charlson Comorbidity Index (CCI). https://www.mdcalc.com/charlson-comorbidityindex-cci. Accessed 21 Dec 2020. 